\title{
UNA CONTRIBUCIÓN AL DESARROLLO SOSTENIBLE: LA FISCALIDAD COMO INSTRUMENTO ECONÓMICO DE PROTECCIÓN AMBIENTAL
}

Ana Paula Basso

Doctora en Derecho Tributario Europeo por la "Universidad de Castilla-La Mancha - UCLM", España, y por la "Università di Bologna", Itália. Profesora de la "Universidade Federal de Campina Grande - UFCG". Profesora del "Programa de Pós-Graduação em Ciências Jurídicas" de la "Universidade Federal da Paraíba UFPB”. Becaria de Pos-Doctorado por el PNPD/CAPES.

Fernanda Holanda de Vasconcelos Brandão Doctora en "Ciências Jurídicas" por la "Universidade Federal da Paraíba - UFPB". Professora de la "Universidade Federal da Paraíba-UFPB". Editora de la "Revista Direito e Desenvolvimento".

\section{Resumen}

La explotación incontrolada del medio ambiente ha amenazado la capacidad asimiladora y regeneradora de la naturaleza. Delante de este problema, hay la necesidad de tomar medidas para garantizar la preservación ambiental, que puedan evitar la perturbación irreversible del equilibrio del entorno natural, cuyas consecuencias son gravosas. Con la referida situación, es importante advertir que debe haber una armonía entre crecimiento económico y medio ambiente, para que se pueda alcanzar el desarrollo sostenible. El objetivo del presente trabajo, es trazar una aproximación a la fiscalidad ambiental, presentando su importancia para conjugar medidas económicas con la tutela del medio ambiente. Se demuestra que, para la consecución de la tutela del medio ambiente, la fiscalidad ambiental puede orientar conductas ambientalmente deseables. Es decir, puede actuar de dos formas, una positiva, por medio de la aplicación de gravámenes más onerosos a las actividades que causen daños al medio ambiente, o de forma negativa, proporcionando una carga tributaria más suave para aquellos que atienden políticas y medidas de conservación ambiental, que vengan a proporcionar el desarrollo sostenible.

\section{Palabras clave}

Fiscalidad ambiental; Desarrollo sostenible; Instrumento económico; Tutela ambiental. 


\section{Abstract}

The uncontrolled exploration of the environment has threatened the assimilative and regenerative capacity of nature. Against this problem, there is a need to take actions aiming at environmental protection, in order to prevent an irreversible trepidation of the balance of the natural environment, which consequences are grievous. Given that situation, it's important to note that there has to be harmony between economic growth and the environment so that we can achieve sustainable development. The objective of this study is to outline an approach to environmental taxation, presenting its importance to matching economic measures with the protection of natural environment. This leads to the conclusion that for the achievement of environmental protection, environmental taxation can guide to a desirable behavior. That is, it can act in two paths; one positive, through the application of more costly taxation to the activities damaging to the environment and the other negative, providing a smoother taxation charge for those whom attending political and environmental conservation measures which will result in sustainable development.

\section{Key words}

Environmental taxation; Sustainable development; Economic instrument; Environmental protection.

\section{Introducción}

Dada la persistente situación de deterioro del medio ambiente, la aplicación del componente ambiental en diferentes sectores de la sociedad se presenta cada vez más relevante. La desestabilización del entorno natural ha despertado cierta inquietud, involucrando la necesidad de realización de medidas preventivas por parte del Estado, de los particulares y de los sectores económicos.

En virtud de esta preocupación, se consideró hablar sobre el concepto de desarrollo sostenible, lo cual debe cubrir el desarrollo de las necesidades presentes sin comprometer las posibilidades de las generaciones futuras, para satisfacer sus propias necesidades. Es preciso pensar en un modelo de desarrollo, que permita el equilibrio adecuado entre el crecimiento económico, el desarrollo social y la tutela del medio ambiente.

La metodología utilizada para la elaboración del presente estudio, tiene por base el método de investigación hipotético-deductivo, en que se parte del análisis del medio ambiente, como elemento esencial para los sectores económicos, siguiendo con la necesidad de su preservación para el desarrollo sostenible y justificando, al final, la implementación de la fiscalidad ambiental como instrumento económico tendiente a incentivar la tutela del medio ambiente. 
El estudio tiene por finalidad, destacar el impacto que suscita la relación medio ambiente y crecimiento económico. Es decir, de un lado está la actividad económica que no puede devastar los recursos naturales y de otro, está la institución de determinado régimen rígido de políticas de conservación ambiental, que no pueden paralizar una actividad económica lícita. Son dos elementos de gran relevancia, pues ambos contribuyen para la calidad y manutención de la vida de las personas. Tanto uno como el otro aspecto no constituyen derecho absoluto, pero ambos deben ser configurados de modo que se limiten recíprocamente.

En la búsqueda del desarrollo sostenible, es necesario el empleo de un mecanismo que permita el equilibrio adecuado entre la protección del medio ambiente, el progreso económico y el desarrollo social. Conforme se podrá verificar en el presente texto, el tributo puede ser un instrumento apto para ello, ya que puede, sobre la autorización del "principio quien contamina paga", desestimular conductas perjudiciales para el entorno o, al contrario, fomentar o estimular otros comportamientos más acordes con la racional utilización de los recursos nacionales, por medio de la graduación (aumento o reducción, respectivamente) del gravamen.

\section{Perspectiva de Medio Ambiente para el Presente Estudio}

El objeto del presente estudio, son las medidas fiscales tendientes a contener la degradación del medio ambiente. Que permitan proponer los aspectos pertinentes hacia este bien esencial, que socialmente se quiere preservar. Ante todo, conviene delimitar el concepto de medio ambiente que se abordará en ésta investigación. Por tratarse de un concepto amplio y complejo, que trae dificultad en determinar una definición propia y específica.

La problemática versa en la variedad y la multiplicidad de ordenamientos que cuidan del referido entorno. Por ejemplo, como en muchos países, incluyendo Brasil y España, el contenido referente al medio ambiente envuelve además del entorno natural, también elementos artificiales, como los monumentos históricos. ${ }^{1}$

1 A ejemplo de Brasil, la regulación del medio ambiente en la Constitución como ambiente natural y cultural está en los artículos 225 y 216, además de la misma trata del medio ambiente artificial en los artículos 184 y 182, que regulan las políticas agrarias y urbanas. Una especial regulación y que posibilita extraer una relación de medio ambiente con sostenibilidad en la Constitución de la República de Brasil está en el artículo 225:

Artículo 225: Todos têm direito ao meio ambiente ecologicamente equilibrado, bem de uso comum do povo e essencial à sadia qualidade de vida, impondo-se ao Poder Público e à coletividade o dever de defendê-lo e preservá-lo para as presentes e futuras geraçóes.

$\$ 1^{\circ}$ - Para assegurar a efetividade desse direito, incumbe ao Poder Público: 
Así como diversos ordenamientos establecen una definición de medio ambiente, en las que se verifica que se trata de un concepto extenso. ${ }^{2}$ Partiendo de los reglamentos que tratan del medio ambiente, infiérase como un conjunto de elementos naturales, artificiales y culturales que proporcionan un desarrollo armónico de la vida. ${ }^{3}$

Partiendo del enfoque del trabajo que se irá desarrollando, se advierte que no se hará un estudio muy extenso sobre el concepto de medio ambiente. Por ello se establece una acotación que pretende enunciar la expresión medio ambiente. Al mencionar medio ambiente en este trabajo, se concibe como "naturaleza" en su sentido económico, o sea, como fuente de recursos de los cuales el hombre depende.

La idea que se quiere exponer, es sobre la esencialidad del medio ambiente para la vida en la Tierra y desarrollo de los seres vivos. Criterio que no puede ser dispensado para el estudio del medio ambiente, es la relación del hombre y la naturaleza, ya que el primero para sobrevivir y desarrollar sus actividades económicas, depende de la segunda. La locución relativa a medio ambiente en la presente investigación, consiste en la representación del entorno natural. En términos generales, es permitido definir el medio ambiente como las condiciones naturales que posibilitan la existencia de vida en la Tierra (ORTEGA ALVAREZ, 2002).

Conforme la relevancia del medio ambiente, a las condiciones de continuidad de la vida en el planeta, que se comprueba en los últimos años, el incremento de la difusión de la preocupación global de su protección. La preocupación no debe ser apenas para reducir

\footnotetext{
I- preservar e restaurar os processos ecológicos essenciais e prover o manejo ecológico das espécies e ecossistemas; II - preservar a diversidade e a integridade do patrimônio genético do País e fiscalizar as entidades dedicadas à pesquisa e manipulação de material genético;

III - definir, em todas as unidades da Federação, espaços territoriais e seus componentes a serem especialmente protegidos, sendo a alteração e a supressão permitidas somente através de lei, vedada qualquer utilização que comprometa a integridade dos atributos que justifiquem sua proteçâa;

IV - exigir, na forma da lei, para instalação de obra ou atividade potencialmente causadora de significativa degradação do meio ambiente, estudo prévio de impacto ambiental, a que se dará publicidade;

$V$ - controlar a produção, a comercialização e o emprego de técnicas, métodos e substâncias que comportem risco para a vida, a qualidade de vida e o meio ambiente;

$V I$ - promover a educação ambiental em todos os niveis de ensino e a conscientização pública para a preservaçâo do meio ambiente;

VII - proteger a fauna e a flora, vedadas, na forma da lei, as práticas que coloquem em risco sua função ecológica, provoquem a extinção de espécies ou submetam os animais a crueldade. [...]

2 La ley 6.938/81 en su artículo $3^{\circ}$, inciso I, del sistema jurídico brasileńo define medio ambiente como: Artigo $3^{\circ}$ - Para os fins previstos nesta Lei, entende-se por:

I - meio ambiente, o conjunto de condiçôes, leis, influências e interações de ordem física, química e biológica, que permite, abriga e rege a vida em todas as suas formas; [...]

3 Así se extrae de la propia referencia del artículo 225 de la Constitución brasileńa. Coincidiendo con lo dicho, el criterio del Tribunal Constitucional de España en -Sentencia- STC 102/1995, de 26 de junio, delimita el medio ambiente como el conjunto de circunstancias físicas, culturales, económicas y sociales que rodean a las personas ofreciéndoles un conjunto de posibilidades para hacer su vida.
} 
problemas ambientales actuales, pero la perspectiva debe ser a largo plazo. Como corolario del crecimiento que se percibe con el pasar de los tiempos y las exigencias cada vez más altas de bienestar, el medio ambiente se encontrará presionado sobre la potencialidad de la existencia de recursos, para atender la demanda y también de absorber la contaminación en su entorno.

En que pese haya intentos dirigidos a la tutela ambiental, infortunadamente, no existe una consciencia seria sobre la necesidad de conservar o mejorar el medio ambiente, por parte de muchas naciones y entes económicos. Partiendo de que preservación del medio ambiente debe ser una actuación global y de esfuerzos múltiples, en este sentido resulta trascendente parafrasear las palabras de Luis Ortega Álvarez (2002, p. 44) en que el mismo resalta que de algún modo es posible conectar la aparición del concepto de medio ambiente como un nuevo valor que debe protegerse frente al resultado del proceso global de concentración de la población en zonas urbanas y del modelo de vida que ello implica.

Tal tarea es una obligación de todos, sea de modo particular, sea de modo colectivo. El medio ambiente se revela como un bien de todos, siendo de interés general y que exige una conducta adecuada de todos que de él disfrutan. No se debe pautar un "no actuar" por un sencillo hecho de ser una preocupación global, que pequeñas medidas de preservación no resultan en nada. Se debe partir, inicialmente, de acciones locales, a través de actuaciones concretas en relación a la actividad dañosa al medio ambiente.

Profusos trabajos aún deben ser hechos para los fines de tutela ambiental. La principal medida que debe ser una preocupación de todos, es que sean incluidos los aspectos ambientales, en la toma de decisiones efectivas de las políticas de desarrollo, asegurando la tutela del medio ambiente, para promover el conocido desarrollo sostenible.

\section{Medio Ambiente y su Aspecto Económico}

En principio, de lo que se observa frente a los fenómenos naturales, como efecto del aniquilamiento continuo de recursos naturales, se constata que hay una constante y creciente preocupación con el medio ambiente que aún no es suficiente. Los resultados del incremento del efecto invernadero no son la excepción, diferentes catástrofes son ocasionadas, como se puede experimentar con las inundaciones y secas que ocurren en diversas partes del mundo.

Es vertiginosa la preocupación con el medio ambiente, ante los impactantes efectos climáticos que se presentan y que se agravan a cada día, comprometiendo la vida en la tierra.

Los deterioros del medio ambiente, son ocasionados en gran parte por la competencia del capitalismo, a través de la desmedida utilización de recursos naturales, sobre 
todo, cuando no hay preocupación con el uso de los recursos no-renovables. Pero, junto a ello, es incongruente afirmar que protección ambiental no pueda conjugarse con desarrollo económico; ya que el primero es la fuente de producción de bienes y generación de energía, que posibilita un incremento conveniente y provisor. El medio ambiente también proporciona la creación de riquezas y empleos. Por ello, se debe alertar en no tener una visión predatoria e inconsciente del medio ambiente.

Cuando se trata de tributación en el ámbito ambiental, la base jurídica primordial es de orden constitucional, lo que no es raro constatar también su delegación en los ordenamientos nacionales. Referida preocupación con el medio ambiente, está relacionada con el desarrollo y además de esto, es atribución de la política fiscal. ${ }^{4}$ No es correcto desasociar el medio ambiente de los sectores económicos y sociales, pues conjuntamente con ellos, componen el desarrollo económico. Es del medio ambiente que se extrae la fuente de la cual se tiene la producción de bienes.

Además, no se debe olvidar que el medio ambiente aunque disfrutado de forma individual por algunos entes económicos, es un bien de interés colectivo y que debe ser protegido por todos. Es por ello que incumbe al Estado, dirigir sus políticas en acciones de preservación del medio ambiente y, sobre todo, que sea asegurado el uso racional de los recursos naturales.

La actuación estatal debe generar resultados positivos al medio ambiente, con la intención de evitar su detrimento, de forma que no haya disensión entre desarrollo económico y medio ambiente. Uno de los substanciales problemas ambientales globales que se presenta está relacionado al llamado "cambio climático" 5 . La degradación del ecosistema frente a los procesos de producción se presenta constante y grande debe ser la preocupación y actuación sobre la problemática.

Diferente no es la consecuencia frente al cambio climático, causado por gases de efecto invernadero, lanzado a la atmosfera, que torna imperiosa la toma de medidas de prevención ambiental. Conforme constata la Organización de las Naciones Unidas, el calentamiento global que amenaza de forma concreta la vida en la Tierra. Además, de esta Organización, el V Programa de medio ambiente elaborado por la Unión Europea,

4 La Carta Magna de la República de Portugal, asevera que es incumbencia del Estado, asegurar que la política fiscal compatibilice desarrollo con protección del medio ambiente y calidad de vida.

5 La atmósfera contiene gases que permiten que ultrapase la gran parte de los rayos solares que llegan hasta la superficie terrestre. Esta radiación produce calor a la superficie de la tierra que también remite parte de la energía absorbida. Esta energía que llega a la atmósfera es retenida por ciertos gases (gases de efecto invernadero) que ocasionan un calentamiento natural en que torna difícil la vida en la Tierra. Si la cantidad de estos gases es acrecida, la detención de energía aumenta y sube la temperatura. Luego, esta alteración en la composición de los gases de efecto invernadero en la atmósfera induce al efecto invernadero, lo que conlleva al calentamiento global y el cambio climático. 
expuso en 1999 una evaluación global, en la cual confirmó como problema ecológico más grave, el derivado del propio cambio climático.

No hay duda, que el efecto invernadero es imputado a la actividad del hombre. Está relacionado a la explotación de combustibles fósiles, -principalmente-, de la concentración de gases compuestos de carbono $(\mathrm{CO}$ y $\mathrm{CO} 2)$ resultantes de su quema.

La problemática ambiental llama la atención en la protección del medio ambiente como condición necesaria para compatibilizar el desarrollo económico con la utilización racional y equitativa de los recursos naturales. O sea, que el crecimiento económico tenga en cuenta el desarrollo sostenible. En el diseño internacional, aunque ya existan esfuerzos dirigidos a enfrentar los problemas relacionados al cambio climático, ellos son pequeños y sutiles, comparado a la dimensión de la problemática y de sus desastrosas consecuencias. Entre muchas, la principal lucha es reducir las emisiones de gases de efecto invernadero. El Protocolo de Kyoto, es una de las importantes aportaciones para el logro de este objetivo. Además, una de las cuestiones debatidas en la Conferencia de las Naciones Unidas, sobre el Medio Ambiente y Desarrollo - Río/92 fue sobre la estabilización del lanzamiento del dióxido de carbono, $\mathrm{CO} 2$, en la atmósfera.

El medio ambiente, es un bien tutelado jurídica y constitucionalmente; los poderes públicos, son los principales responsables para la toma de medidas trascendentales para la preservación del entorno natural, en gestionar acciones a este fin, junto a los sectores económicos.

La preocupación ambiental frente al desarrollo económico, se expone en el ámbito constitucional que trae reflejos en el campo fiscal. Un ejemplo en el Derecho comparado, es la Constitución portuguesa, que atribuye al Estado, la función de asegurar que la política fiscal compatibilice desarrollo con la protección del medio ambiente y calidad de vida.

La tutela ambiental constitucional, tuvo sus primeras promociones en los países europeos, siendo los pioneros aquellos que tuvieran su mudanza en los regímenes dictatoriales, como en el caso de Espańa y Portugal. A su vez, Brasil introdujo en su sistema constitucional, la protección del medio ambiente, con la Carta de 1988 y teniendo a bien considerarlo, formalmente, como un bien jurídico. (NUNES, 2005)

Diversos experimentos de control del referido fenómeno pueden ser gestionados, ya que la materia sobre el medio ambiente puede transponerse a diversas ciencias y en especial, en el ramo del derecho.

La finalidad de protección del entorno natural puede ser averiguada por diferentes formas y con consecuencias diversas. Muestra de lo dicho se tiene en el ámbito del derecho privado, específicamente en Derecho Civil, en que se objetiva reparar los daños ambientales, así como en el derecho público, por medio del Derecho Tributario con una actuación previa con la oferta de beneficios para que el dańo no sea causado o sea 
disminuido, así como en contrapartida, una imposición más pesada para quien utilice técnicas contaminantes de manera que desincentive su empleo y se adopten las técnicas más deseables al medio ambiente.

Al pasar de los tiempos, el Estado ha promovido diversas formas de explotación al proceso de producción, pero sin preocuparse con otras cuestiones y en especial con la conservación del medio ambiente. En efecto, la actuación estatal es sustancial para la toma de medidas protectoras al medio ambiente dentro del sector económico. En este caso, el Estado hace el papel del agente "negociador" de los intereses colectivos e individuales, sea ellos de las presentes o futuras generaciones. (MODÉ, 2003)

Las actuaciones en el medio ambiente, deben ser controladas en la medida que el hombre está incluido en el todo mayor que es el medio ambiente. Con todo, no debe olvidar que los recursos naturales son susceptibles de supresión.

No es una puerilidad insistir en la búsqueda de una convivencia pacífica entre la naturaleza y el desarrollo económico. La posibilidad está en adecuar la producción de bienes a la preservación ambiental. Sin esta preocupación, es difícil no llegar a la destrucción de la especie humana que acaba con una de las esencias de su existencia, en la persecución del desreglado progreso e inconsecuente productividad.

El Derecho tiene importante representación en la defensa del medio ambiente, en instrumentalizar las políticas de gestión social y productiva. El Derecho proclama providencias en la organización de la sociedad y no puede ser diferente a los problemas ambientales.

\section{Desarrollo Sostenible, Interés Económico y Explotación Ambiental}

La locución desarrollo sostenible es una expresión que surgió en 1987, con la obra "Nuestro Futuro Común", conocida como el "Informe de Bruntdtland". Aludido documento resguardó que desarrollo sostenible es atender las necesidades del presente sin comprometer los recursos equivalentes que serán necesarios en el futuro para otras generaciones.

Es posible definir desarrollo sostenible, como aquel desarrollo que atienda las necesidades del presente, sin dejar en riesgo la capacidad de las generaciones futuras, para satisfacer sus propias necesidades. El desarrollo sostenible fue el tema más discutido en la Conferencia de las Naciones Unidas sobre el Medio Ambiente en Río, en el año 1992. Sin embargo, de entre sus discusiones, no fue establecida una definición expresa en la Declaración del evento.

Suele interpretarse su esencia, por el Principio 3 de la Declaración de Río sobre Medio Ambiente y Desarrollo, al declarar que el derecho al desarrollo debe ejercerse en 
forma tal, que responda equitativamente a las necesidades de desarrollo y ambientales de las generaciones presentes y futuras.

Resguarda el principio que sean incorporados los criterios de tutela ambiental en la definición de políticas y de planeamiento de desarrollo. Sobre el tema en cuestión, el desarrollo sostenible se enseńa factible cuando se considera y se promueve el uso de tecnologías renovables.

Es por medio de progresos de mejoría en la productividad de los recursos, que se puede alcanzar el desarrollo sostenible. Tales perfecciones emanan, tanto del avance tecnológico cuanto de la elucidación ética de prioridades.

Convergente con el principio, la Constitución Federal de 1988 de la República de Brasil, contiene la previsión del desarrollo sostenible, al indicar su preocupación con la manutención de un medio ambiente ecológicamente equilibrado y también, al agregar la defensa del medio ambiente como principio orientador de la política económica brasileña.

La particularidad del principio, está en que el desarrollo de la actividad económica, no puede comprometer o poner en riesgo las generaciones futuras. Demandando, así una necesidad, de buscar el equilibro entre la actividad económica, el desarrollo y la protección del medio ambiente.

Debe existir una responsabilidad compartida con equidad, en relación con los recursos naturales y el comportamiento de la actividad económica ante el medio ambiente. Para el equilibrio entre ellos, se debe tener en cuenta, las consideraciones ecológicas en las aplicaciones de políticas económicas y sectoriales, en las decisiones del poder público, así como en la dirección y el desarrollo de procesos de producción y en el comportamiento y elecciones individuales.

El fenómeno del cambio climático es considerado por la comunidad científica, como una de las más serias amenazas para la vida en el planeta. Para que sea mitigada la problemática ambiental, no se puede ignorar la importancia de la intervención de los Estados.

Por lo tanto, es necesaria una regulación jurídica por parte de cada ordenamiento estatal, para hacer frente al grave problema ambiental y se alcance el deseado desarrollo sostenible.

El sector económico, es uno de los principales causantes de los problemas ambientales. Diversas exploraciones del medio ambiente, se justifican en alguna teoría económica.

De manera especial, los modos de producción económica tienen agravado el problema de degradación del medio ambiente, sin preocuparse con la responsabilidad del futuro de la humanidad. Delante de las adversidades ambientales dramáticas se debe tener como prioridad en los debates políticos el control ambiental. Delante de la conjetura, incumbe 
a los Estados formular políticas de acuerdo con las bases de un desarrollo sostenible que son las cuestiones sociales, económicas y ambientales.

Pese la importancia de la protección del medio ambiente, la misma no puede ser vista de manera absoluta, en que se denote una barrera al desarrollo, de tal forma que lo estanque. El desarrollo económico es también un valor que debe ser observado dentro de las políticas estatales.

Entretanto, se está entre la actividad económica, que no puede acabar con la naturaleza y las políticas ambientales, que tampoco pueden paralizar toda una actividad económica imprescindible para la manutención de la vida de las personas.

Apreciase una materia doblemente dividida, por un lado se verifica la actividad económica que no puede ser obstada, y por otro, está la lucha de la preservación ambiental, que es tutelar un bien esencial a la sobrevivencia en la Tierra.

Coexisten dos aspectos importantes; que ambos contribuyen para la calidad de vida de los individuos. Tanto uno como el otro, son incluyentes; pues ninguno de ellos es absoluto y ambos se limitan recíprocamente.

No hay que olvidar que la actuación estatal tiene que ser la más eficiente y eficaz posible. Para ello, se muestra como primordial, el estudio del tributo, como instrumento de intervención en la economía, con el objetivo de proteger el medio ambiente, y, finalmente, atingir el ideal del desarrollo sostenible.

La idea de que el progreso económico y la protección del medio ambiente no se adaptan, no debe ser más aceptada; pues lo que debe resguardarse, es que sus objetivos sean conjugados para alcanzar la deseada calidad de vida.

Con entendimiento diverso, de aquellos que se posicionan en el sentido de que no hay desarrollo, mientras no se pueda causar perjuicio ambiental, hay que aclarar que el medio ambiente y el sector económico, pueden ser asociados y puestos en armonía, en la medida en que se proporcionen medios alternativos y renovables.

No se puede olvidar, que el sector económico depende directamente del medio ambiente. Para que el primero no sea afectado, en la medida que no perjudique el entorno natural, es razonable valerse de diversos instrumentos económicos, incluso beneficios fiscales, que pueden ser ofrecidos al conjunto de empresas y a las actividades del sector económico, preocupadas con la defensa del medio ambiente.

Para ello, se requiere por parte de los Estados, un avance de políticas para el incremento de la consciencia medio ambiental y de la importancia de una innovación de sus respectivas legislaciones.

La estrategia de política ambiental, es elemental para el crecimiento económico sostenible y la ordenada competencia de la economía. Tratase de medidas dirigidas a fomentar la adopción de nuevas tecnologías, que beneficien el medio ambiente y la economía. 
Los ejemplos de acciones son diversos, pueden presentarse como mejoras de eficiencia energética y de recursos que optimizan la productividad y reducen los perjuicios al medio ambiente. A través de esta política, será posible fomentar el crecimiento económico e inclusive, aumentar la oferta de empleo.

Dentro de esta cuestión, uno de los instrumentos de cuño económico es la fiscalidad. Sin embargo, el presente tema en su introducción, se ha hecho mención que la protección ambiental, debe ser analizada con vistas a sus propias limitaciones. Por medio de la fiscalidad ambiental, hay una injerencia del Estado para que el sector privado, sea orientado a tomar medidas no contaminantes y no solamente poner un coste por el daño que a través de una medida persistirá, como ocurre, por ejemplo, con el mercado de emisiones.

\section{Fiscalidad Ambiental como Mecanismo de Alcance al Desarrollo Sostenible}

En consonancia con las políticas generales del medio ambiente, se puede incluir la Organización para la Cooperación y el Desarrollo Económicos (OCDE) como una de sus patrocinadoras. La OCDE considera como instrumentos económicos para la protección del medio ambiente, las medidas que recaen sobre la elección entre diversas opciones tecnológicas o de consumo, por medio de la transformación de las convencionales en términos de costes y beneficios privados.

Considerando esta definición, la OCDE distingue, por lo menos, cinco categorías de mecanismos económicos pertinentes a la tutela ambiental, en las cuales se destacan dos, en razón de la relevancia relativa al presente estudio: a) tasas (o impuesto) y tarifas, que pueden tener función de incentivar o no incentivar determinada actividad o entre ambos; b) subsidios, que tienen la función de ayuda financiera para estimular medidas o actividades involucradas a la reducción de la contaminación.

Hablando del tributo como instrumento económico de tutela ambiental, conviene identificar como se puede clasificar cierta especie tributaria, tal como un tributo ambiental. Para que sea clasificado como tal, es importante considerar la Comisión de la Unión Europea, que advierte sobre la importancia del tributo ambiental, al observar tres elementos indicativos: a) el elemento imponible: que se traduce sobre la base material, sobre la cual la imposición es recogida sobre un impacto negativo sobre el medio ambiente comprobado científicamente; b) la acción de incentivo: por la cual la imposición podría actuar como incentivo económico para la mejora ambiental; c) el vínculo del objetivo declarado: por el cual la voluntad política del legislador es la mejora del entorno natural.

De acuerdo con la propia Comisión, el primer elemento es el que se presenta más eficaz, pues los otros dos son factores exteriores, no objetivos, y dependen de las expectativas y de los juicios subjetivos de la colectividad. 
De conformidad con lo afirmado, sigue la Comisión enseñando que la imposición ambiental, es así caracterizada cuando el imponible es una unidad física (bien como un substituto o derivado), que recurra de una prueba científica de efectos ambientales negativos. Estos impactos negativos pueden ser el deterioro del bien ambiental o una reducción en la oferta de tales bienes.

Según es expuesto por Franco Gallo y Fabio Marchetti (1999), las unidades de medidas para referencia, pueden ser una unidad de substancia emitida o una unidad substitutiva o consecuencial, bien como una unidad de determinado recurso natural. El ejemplo para ello sería un litro de benzina consumida en un motor standard o un vehículo con ciertas características de emisiones.

La Comisión infiere que un tributo ambiental para que sea así configurado, debe tener una relación causal entre la unidad física, que indica determinado deterioro o daño científicamente señalado del medio ambiente, y el imponible del tributo.

Conforme ostenta la Comisión, es relevante la relación causal que debe existir entre el tributo y su unidad física, que representará un perjuicio científicamente comprobado al medio ambiente. Con ello, se puede verificar un tributo caracterizado con una relación directa entre su presupuesto y la unidad física, que produce o puede producir un daño al medio ambiente.

Delante de dicha perspectiva, la finalidad ambiental está ajustada a la estructura del tributo y de esta forma se estaría graduando la imposición, de acuerdo con el deterioro del medio ambiente, científicamente expuesto, conforme la unidad física que determina o también por el respectivo daño ambiental.

Sin embargo, hay que destacar que la finalidad ambiental, se revela en la utilización de un instrumento tributario para el alcance de la tutela ambiental. En otras palabras, se espera un efecto de conservación del medio ambiente, en que la fiscalidad ambiental resulte en un cambio de conducta que reduzca los daños ambientales.

El resultado esperado es que haya un cambio de conducta dirigido a actividades más deseables al medio ambiente, y no que se cree un tributo ambiental que contenga el bien ambiental como elemento de su estructura. Además, en relación al daño ambiental determinante de la unidad física del presupuesto del tributo hay la evaluación de que sea un daño relativo y no absoluto. Es decir, el perjuicio ambiental debe tratarse de deterioro soportable, posiblemente reversible y eventualmente reparable.

Para que haya la tributación con base en la unidad física que produce el daño ambiental, este perjuicio no puede ser "non sostenible". Ya que, según la doctrina que así defiende tal perjuicio, debe ser reprendido por sanciones, con la finalidad de detener la actividad. 
No obstante, no se debe olvidar que los daños ambientales por más triviales que puedan parecer, su constancia y sus resultados a largo plazo pueden ser irreversibles, luego una fiscalidad ambiental debe tener el cuidado de no permitir una incoherente justificación de producir daños ambientales que aún en largo plazo también son irreversibles y non sostenibles.

Delante del desarrollo económico es importante insertar un control sobre él, frente la tutela del medio ambiente, pero en referida injerencia se debe tener el cuidado de no obstarlo de forma injusta ya que se trata de un valor tutelado constitucionalmente.

Los sistemas fiscales nacionales deben presentar en su complejidad, la preocupación con los problemas ambientales, sin negar la relevancia de la tutela ambiental, de forma que proporcione medidas de elecciones fiscales, para la adopción de conductas más adecuadas para el medio ambiente dentro del sector productivo.

A pesar de que será mejor analizado supra, ya se adelanta que la fiscalidad ambiental activa, con la imposición positiva de tributos, debe ser analizada frente la capacidad económica del contribuyente. Esto es, instituir un nuevo tributo ambiental propio o establecer la finalidad ambiental en otro ordinario ya existente, para responder al principio de la capacidad económica, se debe envolver un índice económico, o sea, una evaluación económica.

En pertinente contexto, interesa entonces evaluar la fuerza económica de una emisión contaminante. Todavía, mientras es considerada apenas como una emisión, según se concluye aquí no se verifica un índice económico por sí misma.

Por otro lado, analizando la desventaja que puede acarrear al medio ambiente y comparando los costes no soportados por el ente económico contaminante que deja de adoptar otra técnica menos contaminante, se verifica que el agente contaminante puede lograr una ventaja económica frente a los demás que se preocupan con el medio ambiente.

Lo que se verifica, es una extorsión directa al principio constitucional de la igualdad, donde quien se preocupa con un medio ambiente saludable y que tiene costes para atender este fin, acaba por sufrir un cargo económico más pesado, que aquellos que solo están preocupados con el logro de sus actividades, independiente de los daños ambientales.

Con vistas a la tutela ambiental, el cambio de mentalidad que se debe producir a la sociedad actual, debe alcanzar la actividad que ocasiona el deterioro del medio ambiente. Luego, lo que debe resultar rentable al ente económico, es la posición de asumir el gasto de evitar la contaminación y no el coste del tributo.

\subsection{El Tributo como Instrumento Orientador de Desarrollo Económico y de Tutela Ambiental}

En la actualidad, es visible la proporción del crecimiento económico y de la explotación de los recursos naturales que se presenta de manera severamente predatoria. De 
modo a cambiar esta realidad, hay la necesidad de combinar el derecho tributario y el derecho ambiental, para adecuar la actividad económica y sea dirigida a la preservación ecológica.

En efecto, se puede observar que las cuestiones ambientales están conjugadas a las económicas. Son dos valores relevantes a la sociedad actual y futura, y una eficiente defensa del medio ambiente está sujeta al tratamiento conjugado de las mismas.

El importante aspecto de los tributos ambientales es en relación a su carácter instrumental. Es decir, para la consecución de la tutela del medio ambiente, los poderes públicos pueden adoptar medidas de política económica.

Sin embargo, para que una exacción sea considerada de carácter ambiental, la sustancia o la actividad gravada deben tener un reflejo negativo visible en el medio ambiente, aunque también se consideraría así, cuando tiene un efecto sobre el medio ambiente menos claro, pero su exigencia resulta visiblemente positiva a la tutela ambiental.

Por esta razón, se puede afirmar que la finalidad deseada no es estrictamente fiscal. La esencia de la fiscalidad ambiental es la finalidad extrafiscal de realizar políticas de preservación del medio ambiente.

En otras palabras, un tributo ambiental es así considerado cuando el conjunto de sus elementos estructurales, especialmente que componen el hecho imponible, constituyen un gravamen relacionado directa o indirectamente a fines de protección ambiental.

La fiscalidad ambiental puede actuar de dos formas, una positiva, por medio de aplicación de gravámenes más pesados a actividades contaminantes o de forma negativa, proporcionando incentivos fiscales para la consecución de políticas y medidas de tutela ambiental que reducen el deterioro ambiental.

La idea de defensa del medio ambiente a través de la tributación ambiental, oscila en proporción a la contaminación que sea producida por parte de los entes económicos privados por su actividad dañosa al entorno natural. Mientras se está a producir contaminación, más permanecerá a soportar el encargo tributario. Por otro lado, en la medida en que se contamina menos, reducen las acciones del Estado en fiscalizar el cumplimiento de las normas legales sobre medio ambiente y los perjuicios de la sociedad.

La economía dentro de la fiscalidad ambiental se presenta en dos sentidos, uno será la internalización de los costes recurrentes de la actividad contaminante y el otro será la reducción de los costes públicos con la aplicación de las actividades estatales en fiscalizar y reparar el daño.

Conviene resaltar que a través de la fiscalidad ambiental, se puede proporcionar al agente económico diferentes opciones de elección para adecuar su actividad a un medio ambiente protegido. Ello se torna incomparable a las reglas prohibitivas que no garantizan posibilidades de ajustes por parte del emprendedor. 
Reiterase que la importancia de la utilización de mecanismos fiscales en la protección del medio ambiente, se destaca por su carácter modulador del esfuerzo realizado por el agente económico, dirigido a evitar la contaminación en la medida en que este empeño es premiado por la norma con bonificaciones y exenciones fiscales.

Como muestra se tiene el mecanismo de disponer beneficios fiscales, para aquellos que actúan disminuyendo sus factores contaminantes al investir en tecnologías limpias o se inclinen para el uso de recursos renovables.

Los comportamientos deben ser valorados como legítimo empleo instrumental de cada uno de los actos aplicados. Lo dicho es posible cuando existen diversas alternativas igualmente legales y tratadas de distintas formas por los sistemas fiscales en cada caso.

La cuestión es compleja una vez que se tienen que resguardar dos valores de niveles constitucionales, la libre competencia y el respeto al medio ambiente. Como no se puede abandonar el bienestar económico de los ciudadanos, inevitable es la separación del sector económico con el medio ambiente y esta circunstancia es inferida en diferentes ordenamientos.

Coincidiendo con lo afirmado, identificase la política fiscal española, que es orientada por la protección del entorno natural por intermedio de los incentivos fiscales, y de otros tipos, para que aquellos que tienen comportamientos en conformidad con la conservación del medio ambiente.

La fiscalidad ambiental está sumergida básicamente en la función extrafiscal del tributo. En otras palabras, el objetivo principal es la injerencia en el dominio económico, buscando un efecto diverso de la simple recaudación de recursos financieros.

No obstante, la relevancia de la función fiscal que recae en recaudar impuestos, del mismo modo, es de importancia el medio ambiente, una vez que a través de la recaudación de recursos, tiene como implantar medios dirigidos a la protección ambiental de acuerdo con muchos ordenamientos constitucionales de países involucrados a la protección ambiental.

Sin embargo, si la especie tributaria elegida por el sistema brasileño es el impuesto, habrá el óbice en relación a los recursos recaudados, una vez que no pueden ser vinculados a ningún fondo, por más importante que sea la política de preservación ambiental. La Constitución brasileña no hace excepción a la regla para finalidades ambientales.

En el caso de la tributación activa, se permite llevar a la práctica el principio quien contamina paga, propugnado por la OCDE (1972) y adoptado por los Estados para las medidas de protección ambiental. La aplicación del aludido principio persigue tanto objetivos de eficiencia como de equidad.

El principio de quien contamina paga implica en atribuir al causador del daño ambiental los costos necesarios a la reducción, eliminación o neutralización del deterioro 
del medio ambiente. En otras palabras, importa imponer la responsabilidad en la composición de los costes de las medidas de protección del medio ambiente en los costes de producción.

En este aspecto, el ordenamiento español tiene una política basada en el fundamento de que quien reduce la contaminación tiene reducida su tributación con base en el principio de quien contamina paga.

No obstante, se encuentran cuestionamientos relativos a los incentivos fiscales, porque no se adecuan al principio de quien contamina paga, pues al contrario, implica encargos a toda sociedad. Según los cuestionamientos que se posicionan contrarios a los incentivos fiscales, se tiene el entendimiento que con ellos no se proporciona mejora cualitativa en los procesos de producción, porque en la mayoría de los casos tan-solamente muestra efectividad en la reducción de emisiones o en la producción de residuos industriales.

La posición es pertinente, por ello que se insiste que la medida aplicable debe ser eficaz y se puede complementar que ella también debe ser objetiva. Al indicar objetiva se está relacionando al resultado de la medida, o mejor, es decir que haya un visible resultado en la mejora de la calidad del medio ambiente. Es decir, la ley debe ser específica/objetiva en relación a los resultados que pretende alcanzar. En cuanto al carácter eficaz, concierne verificar como los instrumentos dirigidos a la tutela ambiental permiten atingir eficazmente/efectivamente los fines ambientales.

Relativo a la equidad, consiste que quien contamina en la medida que no soportan los perjuicios ocasionados al medio ambiente, dedujese que utilizan gratuitamente de los bienes públicos pertinentes al entorno natural, de forma que la sociedad sufra los daños causados que estaría "subvencionando" a quien se favorece con la contaminación.

El sistema de tributos está coligado al sistema económico, como una de las formas de reglamentación y planificación de la actividad económica. En el campo de la OCDE los países utilizan cada vez más los tributos con fines de defensa y conservación del medio ambiente.

Las medidas tributarias de carácter ambiental, conciernen en estímulos permanentes al agente económico para que el mismo siga explorando, de acuerdo con sus intereses, la forma más ajustada para la reducción o eliminación del potencial predador del medio ambiente al desarrollar su correspondiente actividad económica.

\subsection{Política Tributaria Ambiental: Conductas Ambientalmente Deseables e Inter- nalización de los Costes Ambientales}

Los tributos cuando son instituidos visan recaudar recursos a los cofres públicos para costear las expensas públicas, siendo caracterizado por el carácter fiscal. No obstante, el 
tributo también puede revestirse de la finalidad extrafiscal, en que la figura tributaria no perseguirá solamente fines recaudatorios.

De forma a ejemplificar lo que fue aseverado, se puede esclarecer que los tributos considerados ambientales que al mismo tiempo que recaudan, pueden dirigir conductas con un gravamen más fuerte para quien no adopta técnicas más limpias de producción. Así, puede haber la redistribución de la recaudación para orientación de las inversiones para sectores productivos o más adecuados al interés colectivo.

Por otro lado, los incentivos fiscales también están envueltos por la extrafiscalidad, una vez que su prioridad no es la recaudación de recursos para los cofres públicos. Son formas para estimular y adoptar medidas más convenientes al orden jurídico.

La tutela ambiental respalda el objetivo de solamente inducir los contribuyentes a no asumir o no continuar con conductas, sin embargo lícitas, que son consideradas impropias en el punto de vista ambiental.

El Estado actúa como agente conductor del comportamiento del sector económico incentivando iniciativas positivas y desincentivando las nocivas al bien común. Conviene decir que un tributo extrafiscal no es así puramente, lo que pasa es que con él se pretende alcanzar finalidades de política económica sin perder la condición de tributo, añadiendo esta configuración de alcanzar otras finalidades a su función fiscal.

Un tributo no surge sin una obligación de pagar y es en ella que se trabaja la función no fiscal. Estos fines fiscales y extrafiscales no son contradictorios, más bien complementarios. A pesar de la ausencia de una característica exclusiva, los tributos pueden ser clasificados como fiscales y extrafiscales en razón de estas características el tributo se orienta de forma preponderante.

Resaltase que la extrafiscalidad no hace que el tributo no tenga que sujetarse a las garantías puestas por el sistema constitucional. No es un régimen de excepción, salvo disposiciones específicas y expresas en la Constitución.

La finalidad extrafiscal está pautada por la generalidad de los principios constitucionales. Asegurando la aplicación de los comandos constitucionales se tendrá la unidad del ordenamiento, con la aplicación armonizada de sus reglas.

Reiterase que es impracticable dividir el medio ambiente de la economía. De esta forma, el Derecho Tributario tiene gran relevancia en la preservación ambiental. En este sentido, es necesario resaltar la trascendente colaboración de los instrumentos de tributación que están siendo usados por los Estados, para el alcance de una política de protección ambiental más objetiva.

Cuando se analiza la fiscalidad ambiental, se puede tratar de tributos propios de carácter ecológico o de los demás tributos existentes con la introducción de medidas que 
incentiven determinadas conductas distintas de aquellas que provocan efectos negativos al crecimiento sostenible.

Para considerar un tributo como ambiental debe investigarse su estructura, que corresponde reflejar la finalidad de incentivar económicamente la protección del medio ambiente. Dentro del estudio sobre medio ambiente y fiscalidad se constata la necesidad de una visión detallada del sistema tributario, exigiendo que ambos sean compatibles. Para ello, es necesario verificar si el sistema posibilita una efectiva protección del medio ambiente. No bastando haber apenas incremento en la recaudación sin la efectiva reducción del impacto ambiental.

Dentro de las formas de gestión de la fiscalidad para la tutela del medio ambiente, se puede valer de la tributación ambiental activa o positiva. La referida forma puede seguir por la aplicación de un tributo ya existente adaptado a los esfuerzos ambientales, como por la creación de un tributo nuevo por el uso del medio ambiente.

Diversos intentos hacen uso de cargas tributarias para combatir la degradación ambiental y el uso inmoderado de los recursos naturales. Los instrumentos fiscales pueden ser tanto como la introducción de nuevos tributos concernientes al medio ambiente como la adecuación del fin de protección ambiental dentro de las estructuras fiscales existentes.

Con ello se estaría creando un gravamen específico relativo a la actividad contaminante, de modo a inducir un nuevo comportamiento deseable y adecuado al entorno natural. Por otro lado, se puede tener la reducción de la contaminación de forma indirecta, una vez que el tributo no presenta directamente un criterio ambiental, siendo que solamente supone una base de él razonablemente vinculada.

Se estaría hablando de introducir elementos ambientales en cualquier de los elementos que forman el tributo, distinguiendo por lograr el efecto extrafiscal por su intermedio. Un ejemplo sería la introducción de alícuotas diferenciadas en un tributo incidente sobre productos conforme su potencial contaminante al medio ambiente.

Parece más aceptable la adaptación del sistema ya existente a los aspectos ambientales, que la creación de nueva imposición. Para ello, son necesarias adaptaciones de modo a armonizar el orden constitucional a la práctica impositiva dirigida a la tutela ambiental.

En cuyo detalle resaltase que el establecimiento de tributos ecológicos debe realizarse con cautela, de tal modo que no se lesionen los principios constitucionales, ni se disfracen como figuras ecológicas que en la verdad son meramente tributos recaudatorios.

Los nuevos gravámenes no se adaptan siempre bien a las categorías tributarias elaboradas por la doctrina, lo que dificulta la configuración de sus elementos esenciales (hecho imponible, sujetos pasivos o elementos de cuantificación). Por tanto, será preciso proceder con rigor en su desarrollo normativo si se desea evitar un peligroso deslizamiento hacia la confusión terminológica y la inseguridad jurídica. 
Como ya se ha aclarado, la fiscalidad ambiental proporciona al agente económico la elección de una opción adecuada a su actividad y sus intereses de forma que atiendan a los intereses ambientales. Los tributos deben servir como instrumentos de intervención estatal en el medio social y en la economía privada.

En la fiscalidad ambiental esta intervención, necesaria, acontece a favor de un comportamiento más favorable de los agentes económicos en relación al medio ambiente. Hay que identificar este importante aspecto, cuando se habla de fiscalidad ambiental en relación a un sector económico. El elemento a ser destacado es que el valor de los costes de producción en razón de la finalidad ambiental, debe ser más alto que el coste de las inversiones en el proceso productivo.

Para combatir los problemas ambientales, la tributación ambiental puede valerse de una actuación coercitiva para compensar las externalidades negativas. Así, no se estaría delante de una intervención estrictamente posterior a la ocurrencia del daño ambiental, se operaría de modo que se evite el respectivo deterioro del medio ambiente y no apenas proceder a reparar los daños en que ya se percibe la existencia de los perjuicios al entorno natural.

La idea del tributo ambiental surgió en 1920 con Arthour Pigou, cuando presentó las fallas de mercado que podrían ser corregidas por el sistema tributario. Según su obra se tiene que los impuestos y las subvenciones pueden interiorizar las externalidades, en otras palabras es seńalar que aquellos efectos que afectan a terceros y que nos son tenidos en cuenta por el mercado, serán soportados por los agentes contaminantes.

Ejemplo de ello, es el productor y el consumidor de electricidad producida por proceso contaminante, que no consideran los perjuicios que la contaminación origina a terceros.

Por consiguiente, el precio de la energía eléctrica sólo expresa los costes y beneficios privados de productores y consumidores y no incluye los costes sociales.

Luego, el modo de producción de energía eléctrica contaminante se beneficia de precios más bajos y se produce en mayor cuantía.

La solución propuesta por Pigou, concierne en corregir los precios considerando los costes sociales producidos por la contaminación, que se agrega al precio de mercado por medio de un impuesto unitario. Este tipo impositivo debe coincidir, idealmente, con el coste marginal de la contaminación en el nivel óptimo de la actividad contaminante.

Incluyendo los costes causados por el daño de la contaminación, se pasa del precio de mercado manifiestamente bajo, a un precio más alto, como consecuencia de una cantidad de producción de mercado excesivamente alta a una más reducida, que resulta socialmente óptima al razonar tanto los beneficios que produce a la sociedad el producto contaminante como los costes de la contaminación que produce. 
No obstante, la administración tributaria no disfruta de todas las informaciones necesarias para establecer un tributo en los moldes propuestos por Pigou, como la función de la demanda de los bienes contaminantes, la función de los costes marginales privados y la función de perjuicios marginales de la contaminación.

La administración tributaria no conoce el nivel de contaminación óptimo, que se traduce en aquél que se maximiza el bienestar social, y ha de accederse con el establecimiento de un standard razonable. O sea, la administración deberá integrarse con objetivos de contaminación que se entiendan razonablemente satisfactorios.

\section{Conclusiones}

Conforme se aprecia del presente estudio, los inconvenientes ambientales han conducido a una preocupación creciente tocante al medio ambiente. La explotación de los recursos naturales ha atingido un nivel alarmante que hace que el Estado promueva soluciones a esta problemática.

Las medidas de intervención estatal dirigidas a la tutela ambiental comportan carácter eminentemente político dentro del sector económico. La fiscalidad, por su vez, revela esta característica política cuando el Estado debe operar buscando fines no meramente recaudatorios. La injerencia estatal siguiendo la extrafiscalidad del sistema tributario, conduce legítimamente los caminos que la economía y el mercado deben perseguir, a estimular los modos de producción y de consumo más convenientes a la sociedad y al desarrollo sostenible.

Los instrumentos fiscales en la tutela ambiental, son considerados incentivos dirigidos a los productores y a los consumidores, para orientarlos a elecciones a favor de comportamientos/actividades más sostenibles en relación al medio ambiente.

La fiscalidad ambiental tiene una finalidad específica y positiva, o sea, está fundamentada en una política de protección ambiental calcada en evitarse el dańo ecológico. Al agente económico se proporciona un margen de opción para adecuación de su actividad, no negando posibilidad de ajuste de su actividad a la defensa del medio ambiente.

Importa destacar que la intervención del Estado en la economía y en los mercados con vistas a la tutela ambiental, no puede ser inflexible interrumpiendo una actividad económica lícita y necesaria al desarrollo de la humanidad. La fiscalidad ambiental consiste en un comando de incentivo al agente económico, para que busque, según sus conveniencias, lo que le sea ventajoso al medio ambiente, incitándolo a comportamientos tendientes a la reducción del potencial contaminante de su actividad.

El estudio no ha dejado de reiterar la duplicidad de la cuestión a que se depara, pues de un lado está la actividad económica que no puede destruir la naturaleza y de otro, los 
mecanismos de tutela ambiental que no pueden paralizar toda una actividad económica lícita y relevante a la sociedad. La idea que se quiere plantear es de equilibrio entre ambos valores, ya que sería arbitrario considerar en absoluto solamente uno de ellos, ya que se limitan recíprocamente.

La protección fiscal del medio ambiente, puede ocurrir estableciéndose gravámenes sobre los comportamientos dañosos al entorno natural, bien como incorporándose beneficios fiscales a la implantación de técnicas menos agresivas al medio ambiente.

La fiscalidad ambiental presenta un atributo preventivo, mientras presupone internalizar las externalidades negativas ambientales, para que el causante del daño al entorno natural soporte los costes ambientales que perjudica a la sociedad, y así, lo induzca a tomar medidas de reducción, eliminación o neutralización del deterioro ambiental.

Así, por fin, importa destacar que el cambio de conducta orientado por la fiscalidad ambiental, que se amoldará acorde a la tutela ambiental, debe alcanzar la actividad que ocasiona el deterioro ambiental. De este modo, sin embargo, lo que debe trascender rentable al ente económico, es asumir el encargo de evitar el impacto ambiental y no el coste del tributo, pues un tributo ambiental ideal es aquél que reduce o no tiene su recaudación, ya que de este modo se alcanza su finalidad esencial que es la reducción/extinción del deterioro ambiental de forma a contribuir para el desarrollo sostenible.

\section{Referencias}

AYALA, P. A. A Proteção Jurídica das Futuras Geraçóes na Sociedade do Risco Global: O Direito ao Futuro na Ordem Constitucional Brasileira. In: FERREIRA, H. S., LEITE, J. R. M., BORATTI, L. V. (Orgs.). Estado de Direito Ambiental: Tendências. Rio de Janeiro: Forense Universitária, 2010.

BASSO, A. P. O sistema tributário como instrumento de proteção ambiental e de desenvolvimento econômico. Revista Direito e Desenvolvimento: revista do curso de direito Unipê, ano 1, n. 1, João Pessoa, 2010.

CASAS AGUDO, D. Aproximación a la categoría jurídico económica del beneficio tributario. In Estudios sobre los beneficios fiscales en el sistema tributario espańol. Coordinación José Antonio Sánchez Galiana. Madrid: Editora Marcial Pons, 2008.

DERANI, C. Curso de Direito Ambiental. São Paulo: Max Limonad, 1997.

FALCÓN Y TELLA, R. Estudios sobre fiscalidad de la energía y desarrollo sostenible. Estudios Jurídicos. Madrid: Instituto de Estudios Fiscales, 2006.

FERNÁNDEZ ORTE, J. La tributación medioambiental - Teoría y práctica. Navarra: Thomzon Aranzadi: 2006. 
FIORILLO, C. A. P. Curso de direito ambiental brasileiro. 13.ed. São Paulo: Saraiva, 2012.

GALLO, F. , MARCHETTI, F. I presupposti della tassazione ambientale. In Rassegna tributaria, n. 1 di gennaio-febbraio 1999.

MODÉ, F. M. Tributação Ambiental - A Função do Tributo na Proteçáo do Meio Ambiente. $1^{\mathrm{a}}$ ed. (2003), Curitiba: Juruá, 2012.

NUNES, C. S. Direito Tributário e Meio Ambiente. São Paulo: Dialética, 2005.

ORTEGA ÁLVAREZ, L. Lecciones de Derecho del Medioambiente. 3a ed., Valladolid: Lex Nova, 2002.

PALAO TABOADA, C. El principio "quien contamina paga” y el principio de capacidad económica. In: TÔRRES, H. T. (Org.). Direito Tributário Ambiental. São Paulo: Malheiros Editores, 2005.

ROSEMBUJ, T. La convergencia entre el Derecho Ambiental y el Derecho Tributario. Quincena Fiscal - Revista de Actualidad Fiscal, n. 13, Julio de 1997.

SALVINI, L. Questioni attuali sulla fiscalità del settore energetico. Rassegna Tributaria, n. 6, Novembre-Diciembre de 2007, Italia.

SCHOUERI, L. E. Normas tributárias indutoras e intervenção econômica. Rio de Janeiro: Forense, 2005.

TRENNEPOHL, T. D. Incentivos fiscais no direito ambiental. São Paulo: Saraiva, 2008.

VAQUERA GARCIA, A. La fiscalidad ambiental: algunas reflexiones actuales. Nueva Fiscalidad, n. 3, Marzo de 2006.

VERRIGNI, C. La rilevanza del principio comunitario "chi inquina paga" nei tributi ambiental. In: Rassegna tributaria, n. 5 di settembre-ottobre 2003.

VIEIRA, A. C. O princípio da precaução e a extrafiscalidade na tributação ambiental. Revista Direito Tributário Atual, n.32, 2014. 